\title{
GESTÃO INTERNACIONAL DE PESSOAS: NOVAS POSSIBILIDADES DE PESQUISA
}

\section{INTERNATIONAL MANAGEMENT OF PEOPLE: NEW RESEARCH POSSIBILITIES}

\author{
André Luiz Mendes Athayde \\ Doutorando em Administração - Universidade de Brasília (UnB). Docente da Universidade Federal de Minas Gerais (UFMG). \\ Montes Claros, MG, Brasil \\ E-mail: andreluizathayde@outlook.com \\ Claudia Luciana Tolentino Santos \\ Doutoranda em Administração - Universidade de Brasília (UnB). Docente da Universidade Estadual de Montes Claros (Unimontes). \\ Montes Claros, MG, Brasil \\ E-mail: cau.tolen@gmail.com

\section{Gisela Demo Fiuza} \\ Doutora em Psicologia Social, do Trabalho e das Organizações - Universidade de Brasília (UnB). Pós-Doutorado em Management \& \\ Organizations pela University of California, Los Angeles (UCLA). Docente da Universidade de Brasília. \\ Brasília, DF, Brasil \\ E-mail: giselademo@gmail.com \\ Ana Carolina Rezende Costa \\ Doutoranda em Administração - Universidade de Brasília (UnB). Administradora na Universidade de Brasília (UnB). \\ Brasília, DF, Brasil \\ E-mail: carolrezendecosta@gmail.com
}

\section{RESUMO}

Objetivando verificar como o estudo no campo da Gestão Internacional de Pessoas reflete-se em nível nacional, esta pesquisa buscou dar sequência à bibliometria de Silva, Orsi e Nakata (2013) que teve como marco final o ano de 2011. Identificaram-se os padrões demográficos, metodológicos e temáticos de artigos sobre o assunto, publicados entre janeiro de 2012 e junho de 2017, em 32 periódicos brasileiros de primeira linha. Os resultados apontaram a necessidade de se abordarem, dentre outros temas, o papel e a importância da Gestão Internacional de Pessoas, fugindo de um enfoque puramente operacional e burocrático sobre os processos de Expatriação. Conclui-se que o fato de a temática ser pouco estudada no país traz, por si, grandes oportunidades de pesquisa que possam dar base científica à gestão organizacional, tornando-a mais efetiva.

Palavras-chave: Gestão Internacional de Pessoas. Revisão Bibliométrica. Produção Nacional. Institucionalização da Pesquisa no Brasil. Agenda de Pesquisa.

Data de submissão: 6 de março de 2018.

\begin{abstract}
Aiming to verify how the study on the International Management of Human Resources field is reflected at the national level, this research sought to follow the bibliometry of Silva, Orsi and Nakata (2013), which had the year of 2011 as the final mark. Demographic, methodological and thematic standards were identified on articles about the subject, published between January 2012 and June 2017 in 32 first-class Brazilian journals. The results pointed out the need to address, among other issues, the role and importance of the International Management of Human Resources, avoiding a purely operational and bureaucratic approach on the processes of Expatriation. It is concluded that the fact that the subject is little studied in the country, brings, by itself, great research opportunities that can give scientific basis to the organizational management, making it more effective.
\end{abstract}

Keywords: International Management of People. Bibliometric Review. National Production. Institutionalization of Research in Brazil. Research Agenda.

Data de aprovação: 22 de agosto de 2018. 


\section{INTRODUÇÃO}

O processo de internacionalização tem marcado a história recente de economias emergentes, como o caso do Brasil. $O$ ano de 2006, por exemplo, ganhou destaque por ter sido o primeiro ano em que houve maior investimento das empresas brasileiras fora do país do que aquilo que as empresas internacionais investiram em empresas no Brasil (FLEURY e FLEURY, 2007).

Nessa perspectiva, a globalização é caracterizada não apenas pela elevação do movimento de capital e produtos, mas também pela mobilização de trabalhadores em diferentes mercados (SILVA, ORSI e NAKATA, 2013). Nesse cenário de internacionalização, Hill (2005) ressalta a importância de que a gestão de pessoas seja revista quanto aos processos de recrutamento e seleção, gestão de expatriados, treinamento e desenvolvimento, dentre outros subsistemas. Tendo em vista que a área de recursos humanos é crítica para o sucesso de negócios internacionais (VANCE e PAIK, 2006), torna-se estratégico entender como a gestão de pessoas deve ser trabalhada nesse cenário multicultural, quais desafios existentes e quais adaptações se fazem necessárias.

Assim, a internacionalização, a elevação da mobilidade de profissionais, a procura intensiva por talentos em nível mundial e a demanda por líderes globais compõem o conjunto de efeitos subordinados em maior ou menor grau às condições externas da empresa. Esses fatores demonstram a importância de transformações rápidas o suficiente para que as organizações se mantenham competitivas, tendo como referência a gestão de recursos humanos em escala mundial (LIMA, 2016). As dificuldades em gerir pessoas globalmente são oriundas dos diferentes ambientes em que as multinacionais operam, isso porque as características locais impactam no desenho dos modelos de gestão (KOSTOVA, ROTH e DACIN, 2008).

Silva, Orsi e Nakata (2013) destacam que o campo de estudo em Gestão Internacional de Recursos Humanos é recente tanto no contexto internacional quanto no brasileiro. No caso do Brasil, essa incipiência é justificada em boa parte devido à recente internacionalização das organizações nacionais. Os autores avaliaram que, em 2012, dos 35 grupos de pesquisa registrados no Conselho Nacional de Desenvolvimento Científico e Tecnológico (CNPq), ligados ao tema internacionalização de empresas, apenas dois apresentavam uma abordagem relativa à gestão de recursos humanos e gestão cultural.

Nesse sentido, o objetivo geral do presente estudo foi analisar a produção nacional quanto à Gestão Internacional de Pessoas entre janeiro de 2012 e junho de 2017. A escolha do recorte temporal baseou-se no marco final da bibliometria realizada entre 2001 e 2011 por Silva, Orsi e Nakata (2013) em que avaliaram a produção nacional e internacional acerca do tema. Não obstante, a presente revisão focou mormente a produção nacional. Em termos metodológicos, utilizou-se o estudo bibliométrico que, para Araújo e Alvarenga (2011), retrata o desenvolvimento de uma área do conhecimento apontando lacunas teóricas e empíricas da mesma. Ademais, a Bibliometria quantifica as características dos estudos analisados (TAGUE-SUTCLIFFE, 1992).

O artigo está dividido em cinco partes, inclusa esta introdução. Na segunda seção, são apresentadas considerações acerca da Gestão Internacional de Pessoas, evidenciando o campo de pesquisa na área. $\mathrm{Na}$ parte seguinte, exploram-se os procedimentos metodológicos da pesquisa e, em seguida, a exposição e análise dos resultados com proposição de agenda de pesquisa para o contexto brasileiro. Por fim, são expostas as conclusões do trabalho, evidenciando suas contribuições e limitações. 


\section{REFERENCIAL TEÓRICO}

Armstrong (2011) define a Gestão Internacional de Recursos Humanos como o processo de planejamento de como desenvolver e implementar as melhores políticas e práticas de gestão de pessoas em diferentes contextos internacionais de empresas multinacionais. $O$ autor salienta alguns dos principais fatores que influenciam a Gestão Internacional de Pessoas, tais como os impactos da globalização, a influência das diferenças ambientais e culturais, a centralização ou descentralização da administração, a variação de políticas e práticas de recursos humanos entre os diferentes países, dentre outros.

Taylor, Bechler e Napier (1996) acrescentam que, nesse contexto, a Gestão Internacional de Pessoas inclui não apenas as operações estrangeiras, mas também as da sede ou matriz. Os autores definem o sistema de Gestão Internacional de Pessoas como o aglomerado de processos que objetivam atrair, desenvolver e manter os recursos humanos de uma multinacional.

Dessa maneira, o objetivo maior da Gestão Internacional de Pessoas é fazer com que a empresa multinacional obtenha sucesso em nível global. Nesse cenário, existem cinco fatores relevantes que precisam ser levados em conta: aspectos estratégicos da multinacional; fatores externos; fatores internos; políticas e práticas internacionais de recursos humanos e eficácia da multinacional. Dentre esses fatores, ganha destaque a questão do expatriado, por apresentar desafios quanto à sua movimentação, adaptação, aumento de custos e, em algumas circunstâncias, até a necessidade de repatriação (SCHULER e TARIQUE, 2007), devendo ser tratado com mais atenção pela área de Gestão Internacional de Pessoas (CALDERÓN, GUEDES e CARVALHO, 2016). Schuler e Tarique (2007) evidenciam que estudos concernentes à Gestão Internacional de Recursos Humanos são escassos, sendo que a maioria das pesquisas existentes foca em questões operacionais de expatriados, detalhando o processo de expatriação e suas respectivas políticas e práticas.

De acordo com Bueno e Freitas (2011), a mobilidade internacional não se limita apenas à questão geográfica, mas faz com que o indivíduo tenha desejo em interagir culturalmente e busque melhorar seu desempenho tanto profissional quanto pessoal, por meio da experiência no exterior, além de ser uma necessidade das organizações multinacionais.

Nesse contexto, empresas globais demandam estratégias de recursos humanos específicas para administrar possíveis conflitos que podem surgir a partir da internacionalização da mesma, ficando a reboque da posição estratégica dos negócios sobre o que deve ser global e o que deve ser local (NOGUEIRA, BARRETO e DELGADO, 2013).

Os sistemas etnocêntricos e paroquiais de $\mathrm{RH}$ e a herança das políticas até então focadas em um único país infelizmente ainda são as barreiras mais comuns para a implantação de processos organizacionais globais (PUCIK, 1997). O principal desafio de multinacionais é administrar de forma eficiente os conflitos que surgem com a internacionalização das empresas, oriundos da escolha entre o que deve ser considerado no âmbito global e o que precisa ser encarado como local. Porém, o desafio ultrapassa a questão de centralizar e descentralizar, sendo necessário atingir um equilíbrio entre ser centralizado para a integração e coordenação global e ser descentralizado para as responsabilidades locais (VANCE e PAIK, 2006).

A dimensão cultural também é de grande importância no estudo dos processos de internacionalização que envolvem pessoas. Nesse sentido, a inadequada adaptação do expatriado devido ao choque cultural é um dos desafios que devem ser compreendidos (GALLÓN, GARAY e BITENCOURT, 2012). Para Tanure e 
Duarte (2006), quando entram em mercados internacionais, as empresas enfrentam o desafio de compreender as especificidades do outro país concernente aos seus padrões culturais, ao comportamento do consumidor, ao ambiente institucional, dentre outros pontos. O grau de similaridade ou diferença quanto ao país da empresa matriz faz com que alguns locais sejam mais atrativos do que outros, sendo que é essencial evitar que os procedimentos organizacionais adotados entrem em choque com os valores fundamentais das pessoas de determinada cultura.

Nessa acepção, Hofstede (2011) desenvolveu um trabalho clássico, objetivando entender as dimensões culturais em vários países e o quanto essas dimensões influenciam as organizações. Ele estabeleceu seis dimensões, a saber: distância do poder - o grau de desigualdade considerado normal pelas pessoas; individualismo - o grau com que as pessoas preferem atuar individualmente em relação a membros de outros grupos; masculinidade - o grau em que as pessoas são ambiciosas, têm posições firmes, são preocupadas com o dinheiro e admiram o que é grande e forte; aversão à incerteza - o grau com que as pessoas de um país preferem situações estruturadas a situações desestruturadas; orientação de longo prazo - o grau de adoção de comportamentos voltados para recompensas futuras; indulgência x restrição - a indulgência se relaciona à gratificação e à restrição aos desejos humanos relacionados com o gozo da vida. Para PUCIK (1997), as tentativas de gerenciamento universal negligentes aos aspectos culturais locais podem gerar sérios prejuízos, em especial em cargos de liderança.

Uma profícua Gestão Internacional de Pessoas requer que alguns passos sejam tomados. A empresa matriz precisa reconhecer que as suas subsidiárias estrangeiras podem ter caminhos de gerenciar recursos humanos que sejam mais efetivos localmente. Outrossim, a empresa matriz precisa não apenas conhecer as diferenças culturais, mas também querer discuti-las e utilizá-las para o benefício da organização. Ademais, é necessário que todas as partes interessadas compreendam que maneiras mais criativas e efetivas de gerenciar recursos humanos podem ser desenvolvidas transculturalmente (LAURENT, 1986).

Quanto ao processo de recrutamento e seleção internacional, Miller (1973) diz que, a princípio, ele não se diferencia do doméstico, isto é, os elementos principais a serem considerados continuam os mesmos: as características do indivíduo, o ambiente e as necessidades do cargo. Porém, ele ressalta que a pessoa selecionada para trabalhar no exterior precisa demonstrar maior capacidade de adaptação e flexibilidade, haja vista que precisará enfrentar situações diferentes de uma pessoa que trabalha em um ambiente doméstico. Com a internacionalização das organizações, gerir talentos passou a significar uma necessidade competitiva contínua por profissionais não apenas qualificados, mas com uma mentalidade global (GUO e AL ARISS, 2015).

No tocante ao processo de treinamento e desenvolvimento, as organizações globais normalmente dedicam seus esforços na estruturação de universidades corporativas no intuito de difundir a cultura e valores comuns bem como para promover mudanças céleres em toda a organização. Por meio dessas iniciativas, os profissionais e líderes globais são auxiliados no desenvolvimento de suas competências internacionais tais como habilidades em outros idiomas e conhecimento de leis de outras culturas (NOGUEIRA, BARRETO e DELGADO, 2013).

A remuneração também apresenta particularidades na Gestão Internacional de Pessoas. Reynolds (2000) afirma que os sistemas de remuneração variam no mundo e essas variações são provenientes essencialmente das diferentes culturas e influências históricas de cada país. A título de exemplo, o 
individualismo e o alto desempenho são intensamente encorajados nos Estados Unidos, enquanto a responsabilidade social é muito enfatizada na Europa continental. Também não se pode deixar de citar o tradicional modelo japonês que leva em conta a idade e o tempo de empresa como fortes determinantes da remuneração.

Outro assunto comumente discutido na Gestão Internacional de Pessoas é o processo de expatriação, isto é, a mudança de um indivíduo para outra nação. A gestão desse processo é desafiadora porque o custo de expatriação de um colaborador é alto, além das dificuldades de adaptação do mesmo a outra cultura (BOLINO e FELDMAN, 2000). É necessário que se tenha clareza acerca do objetivo por trás da expatriação a fim de que ela seja bem-sucedida. Adicionalmente, a possibilidade de repatriação precisa ser considerada, ou seja, a volta do colaborador ao seu país de origem. Se não é dado foco também ao processo de retorno, parte do investimento feito na expatriação pode ser perdida, haja vista que a transferência de conhecimento do colaborador na sua volta poderá ser prejudicada. É importante notar que, quando o executivo volta, as suas percepções podem ser bem diferentes das que possuía inicialmente antes da expatriação e sua aspiração de carreira pode ter sofrido mudanças significativas (TANURE e DUARTE, 2006).

A pesquisa Mobility Brasil (2016) é um estudo de referência e apoio ao trabalho de profissionais de Recursos Humanos envolvidos com a mobilidade internacional no Brasil. A sua quinta edição foi desenvolvida em parceria com a Worldwide ERC, a maior associação internacional de empresas relacionadas à mobilidade, com o apoio da FIA - Fundação Instituto de Administração. Em suma, a pesquisa foi respondida por 210 empresas multinacionais com fluxo de expatriados envolvendo o Brasil, durante os meses de setembro e outubro de 2016. Dentre os achados do estudo, destaca-se que a principal razão para um profissional aceitar uma transferência internacional é a perspectiva de longo prazo e não os eventuais ganhos de curto prazo. Além disso, foi detectado que a continuidade da crise econômica brasileira gerou importantes impactos, tais como a elevação do interesse de profissionais por posições no exterior, significativa queda do volume total de profissionais expatriados (tanto de estrangeiros morando no Brasil quanto de brasileiros morando no exterior) e mudança do perfil das posições ocupadas por estrangeiros no Brasil, com progressiva redução das posições técnicas e operacionais. Concernente aos principais motivos do insucesso da transferência internacional, ganharam evidência as questões pessoais e familiares bem como as dificuldades de adaptação cultural e social da família. No tocante aos destinos dos brasileiros no exterior, destacam-se Europa (40\%) e Estados Unidos (31\%).

A produção empírica recente concernente ao tema desvela a relevância que ele tem alcançado na gestão organizacional atualmente. Gallon, Scheffer e Bitencourt (2014) realizaram estudo de caso em uma empresa que contava com um programa de expatriação há 12 anos e detectaram que a mesma carecia de políticas e práticas mais estruturadas, pelo fato de a internacionalização ter tomado uma dimensão maior do que a organização estava preparada para lidar. Os autores evidenciaram que, apesar de a expatriação permitir possibilidades de crescimento para os profissionais e para a empresa, também apresenta muitos desafios a serem superados, como o aprimoramento do treinamento do processo, planejamento da repatriação, valorização e retenção dos repatriados.

Remondes e Vinhas (2014) avaliaram a sensibilidade de duas empresas portuguesas para o processo de expatriação e repatriação de seus colaboradores, constatando que, apesar de se destacarem positivamente quanto ao acompanhamento dos colaboradores e familiares durante o período no exterior, 
descuidavam-se da reprodução do trabalho desenvolvido pelos expatriados. Ademais, as duas empresas não pensavam de forma estruturada a respeito do cargo a ser atribuído ao colaborador após o seu retorno ao país de origem.

Ainda no contexto de expatriação, Simonelli e Araújo (2016) realizaram uma pesquisa com 217 casais com um dos cônjuges na posição de expatriado, objetivando avaliar a relação entre a adaptação dos mesmos com o desempenho do expatriado. Os resultados sugeriram que a adaptação do cônjuge pode exercer uma influência indireta no desempenho do expatriado, mas revelaram que a adaptação do expatriado modera a relação entre essas variáveis. Assim, os achados reforçaram a ideia de que se deve investir em suporte organizacional para facilitar um melhor ajuste do expatriado e seu cônjuge à cultura do país de destino e promover um desempenho individual superior.

Nessa ótica, o estudo de Calderón, Guedes e Carvalho (2016) buscou problematizar as experiências de brasileiros expatriados para revelar os desafios e as oportunidades com os quais se deparam em outras culturas. Como resultado, os autores destacam os desafios da fragilidade da adaptabilidade antecipada, das estratégias de retorno, do repatriamento e suas implicações para o plano de carreira, assim como a necessidade de programas específicos de treinamento intercultural. Por outro lado, os relatos dos expatriados apontam conotações positivas às oportunidades profissionais e pessoais das missões internacionais.

A seguir, serão detalhados os procedimentos metodológicos que foram realizados para a elaboração do presente estudo.

\section{PROCEDIMENTOS METODOLÓGICOS}

Do ponto de vista dos objetivos, a presente pesquisa caracterizou-se como descritiva, uma vez que buscou identificar características da produção acadêmica brasileira quanto à Gestão Internacional de Pessoas, bem como exploratória, por ter permitido um maior conhecimento sobre o assunto. A fim de atingir seu objetivo, a pesquisa utilizou a técnica da análise bibliométrica que, para Tague-Sutcliffe (1992), é o estudo quantitativo da produção, disseminação e uso da informação registrada e, conforme Araújo e Alvarenga (2011), contribui para a análise do cenário de pesquisa em um país acerca de um determinado campo do conhecimento.

Nesta pesquisa, objetivando gerar uma revisão que refletisse padrões da produção nacional dos veículos mais valorizados no meio acadêmico, foram selecionados os periódicos brasileiros da área de Administração com estrato igual ou superior a B2 segundo a classificação Qualis da Coordenação de Aperfeiçoamento de Pessoal de Nível Superior (CAPES) para o Quadriênio 2013-2016, disponível na Plataforma Sucupira. Seguindo esse critério, foram selecionados 32 periódicos de Administração, a saber: BAR. Brazilian Administration Review; BBR. Brazilian Business Review; Cadernos EBAPE.BR (FGV); Organizações \& Sociedade (Online); RAC. Revista de Administração Contemporânea (Online); RAE. Revista de Administração de Empresas; RAP. Revista de Administração Pública; RAUSP - Revista de Administração (São Paulo. Online); Revista Brasileira de Gestão de Negócios (Online); BASE - Revista de Administração e Contabilidade da UNISINOS; Gestão \& Produção (UFSCAR. Impresso); RAI: Revista de Administração e Inovação; RAM. Revista de Administração Mackenzie (Online); REA Revista de Administração da UFSM; READ. Revista Eletrônica de Administração; RECADM: Revista Eletrônica de Ciência Administrativa; REGE. 
Revista de Gestão USP; Revista de Ciências da Administração; Revista Portuguesa e Brasileira de Gestão (Rio de Janeiro); E\&G - Revista Economia e Gestão; FACES: Revista de Administração (Belo Horizonte. Online); Gestão \& Planejamento; Gestão \& Regionalidade (Online); Organizações Rurais e Agroindustriais (UFLA); Revista de Administração da UNIMEP; Revista Desenvolvimento em Questão; Revista do Serviço Público; Revista Eletrônica de Estratégia \& Negócios; Revista Iberoamericana de Estratégia; Revista Organizações em Contexto (Online); Revista Pretexto; Teoria e Prática em Administração.

A partir da identificação das fontes, foi realizado o levantamento de artigos sobre o tema Gestão Internacional de Pessoas em todos os volumes e números publicados no período de janeiro de 2012 a junho de 2017. A busca dos artigos utilizou a plataforma de busca dos sítios eletrônicos dos próprios periódicos. A seleção foi feita pela busca de termos ou descritores, previamente estabelecidos no título, resumo e palavraschave de cada artigo publicado, a saber: Gestão Internacional de Pessoas; Gestão Global de Pessoas; Gestão Intercultural de Pessoas; Gestão Internacional de Recursos Humanos; Gestão Global de Recursos Humanos; Gestão Intercultural de Recursos Humanos; RH Internacional; RH Global; RH Intercultural; Gestão Internacional; Gestão Global; Gestão Intercultural; Internacionalização; Gestão de Expatriados; Expatriação; Repatriação. A busca dos referidos termos se deu também em Inglês, haja vista a possibilidade de publicação nesse idioma em alguns dos periódicos analisados. Os termos foram selecionados a partir da sua recorrência durante a elaboração do referencial teórico deste trabalho.

Após identificação de todos os artigos, partiu-se para a classificação e análise dos mesmos. Para o processo de análise, foi realizada a leitura dos títulos, resumos, palavras-chave e, quando necessário, buscaram-se esclarecimentos na introdução e nas seções de metodologia e discussão dos resultados das produções. Após uma amostra inicial de 130 artigos, foram descartados aqueles cujo foco principal não era a Gestão Internacional de Pessoas. Os artigos descartados focavam majoritariamente no processo de internacionalização com abordagem restrita a questões de comércio exterior, riscos políticos, resultados financeiros, marketing, tipologias, trajetórias e grau de internacionalização, inovação, estratégia de negócios, modos de entrada no mercado externo, dentre outros assuntos sem vínculo direto com a área de recursos humanos.

Como resultado final, foram selecionados 16 artigos para análise pormenorizada cujos títulos e respectivos periódicos estão resumidos no Quadro 1. Os artigos selecionados foram analisados de acordo com 12 categorias, a saber: nome do periódico; ano de publicação; enquadramento do estudo; instituições de origem dos autores; autores que mais publicaram no período; objetivos do estudo; abordagem metodológica; natureza; setor da economia em que as empresas pesquisadas se inserem; ramo de atuação das empresas pesquisadas; instrumentos de coleta de dados; e técnicas de análise de dados.

Por fim, foram identificados os grupos de pesquisa que trabalham com o tema Gestão Internacional de Pessoas, por meio da busca textual no diretório da Plataforma Lattes, em julho de 2017, utilizando os mesmos descritores supracitados. As principais etapas do estudo estão sumarizadas no Quadro 2. 
Quadro 1 - Artigos selecionados para análise

\begin{tabular}{|c|c|}
\hline Título Do Artigo & Nome do Periódico/Classificação Qualis \\
\hline $\begin{array}{l}\text { "Eu fui, voltei e ninguém viu”: um estudo sobre a expectativa de } \\
\text { carreira após a repatriação em uma empresa brasileira. }\end{array}$ & Cadernos ebape.br (FGV). Qualis A2 \\
\hline $\begin{array}{l}\text { Drivers of human resource management competences development } \\
\text { in Brazilian multinational subsidiaries: a multilevel research. }\end{array}$ & $\begin{array}{l}\text { RAUSP - Revista de Administração (São } \\
\text { Paulo. Online). Qualis A2 }\end{array}$ \\
\hline $\begin{array}{l}\text { Adaptação de expatriados organizacionais e voluntários: } \\
\text { similaridades e diferenças no contexto brasileiro. }\end{array}$ & $\begin{array}{l}\text { RAUSP - Revista de Administração (São } \\
\text { Paulo. Online). Qualis A2 }\end{array}$ \\
\hline Estilos de vida de trabalhadores em contexto de expatriação. & $\begin{array}{l}\text { RAM. Revista de Administração Mackenzie } \\
\text { (Online). Qualis B1 }\end{array}$ \\
\hline $\begin{array}{l}\text { Valores pessoais como antecedentes da adaptação transcultural de } \\
\text { expatriados. }\end{array}$ & $\begin{array}{l}\text { RAM. Revista de Administração Mackenzie } \\
\text { (Online). Qualis B1 }\end{array}$ \\
\hline $\begin{array}{l}\text { Qualidade de vida no trabalho de profissionais expatriados para Índia } \\
\text { e China. }\end{array}$ & $\begin{array}{l}\text { READ. Revista Eletrônica de Administração. } \\
\text { Qualis B1 }\end{array}$ \\
\hline $\begin{array}{l}\text { Para além dos aspectos tecnológicos na transferência intercultural de } \\
\text { conhecimento: o papel da área de recursos humanos internacional. }\end{array}$ & $\begin{array}{l}\text { READ. Revista Eletrônica de Administração. } \\
\text { Qualis B1 }\end{array}$ \\
\hline $\begin{array}{l}\text { Mentalidade Global e RH Internacional em Empresas Multinacionais } \\
\text { Brasileiras do Segmento de Construção Pesada. }\end{array}$ & REGE. Revista de Gestão USP. Qualis B1 \\
\hline $\begin{array}{l}\text { Adaptação e validação de instrumento de medida de competências } \\
\text { interculturais para estudantes universitários brasileiros. }\end{array}$ & REGE. Revista de Gestão USP. Qualis B1 \\
\hline $\begin{array}{l}\text { Políticas de Recrutamento e Seleção nos Programas de Expatriação: } \\
\text { Uma Comparação entre as Transnacionais Brasileiras. }\end{array}$ & $\begin{array}{l}\text { Revista Desenvolvimento em Questão. } \\
\text { Qualis B2 }\end{array}$ \\
\hline Processo de expatriação: um modelo com fases e práticas. & $\begin{array}{l}\text { Revista Eletrônica de Estratégia \& Negócios. } \\
\text { Qualis B2 }\end{array}$ \\
\hline $\begin{array}{l}\text { Repatriados brasileiros de transnacionais: fatores relevantes para sua } \\
\text { permanência. }\end{array}$ & $\begin{array}{l}\text { Revista Eletrônica de Estratégia \& Negócios. } \\
\text { Qualis B2 }\end{array}$ \\
\hline $\begin{array}{l}\text { Fatores Extrínsecos e Intrínsecos da Estratégia de Expatriação - uma } \\
\text { Proposta de Framework para as Subsidiárias Estrangeiras. }\end{array}$ & $\begin{array}{l}\text { Revista Iberoamericana de Estratégia. } \\
\text { Qualis B2 }\end{array}$ \\
\hline $\begin{array}{l}\text { Aspectos Organizacionais da Internacionalização de Universidades } \\
\text { Corporativas Brasileiras. }\end{array}$ & $\begin{array}{l}\text { Revista Organizações em Contexto (Online). } \\
\text { Qualis B2 }\end{array}$ \\
\hline $\begin{array}{l}\text { Distância psicológica em internacionalização de empresas: reflexões } \\
\text { sob o ponto de vista do estrangeiro. }\end{array}$ & Revista Pretexto. Qualis B2 \\
\hline $\begin{array}{l}\text { Programas Trainee e Expatriação como Processos que Evidenciam a } \\
\text { Importância Estratégica da Gestão de Recursos Humanos. }\end{array}$ & $\begin{array}{l}\text { Teoria e Prática em Administração. Qualis } \\
\text { B2 }\end{array}$ \\
\hline
\end{tabular}

Fonte: Elaborado pelos autores 
Quadro 2 - Etapas adotadas no estudo

\begin{tabular}{|c|l|l|}
\hline Etapa & \multicolumn{1}{|c|}{ Descrição } & \multicolumn{1}{|c|}{ Quantidade obtida } \\
\hline Etapa 1 & $\begin{array}{l}\text { Elaboração do Referencial Teórico sobre o tema Gestão Internacional de } \\
\text { Pessoas. }\end{array}$ & Não se aplica \\
\hline Etapa 2 & $\begin{array}{l}\text { Busca de artigos nos 32 periódicos científicos tomados como base, } \\
\text { através dos descritores mais recorrentes no Referencial Teórico. }\end{array}$ & 130 artigos \\
\hline Etapa 3 & $\begin{array}{l}\text { Filtro dos artigos com relação direta ao tema Gestão Internacional de } \\
\text { Pessoas para posterior análise, através da leitura dos títulos, resumo e } \\
\text { palavras-chave. }\end{array}$ & 16 artigos \\
\hline Etapa 4 & $\begin{array}{l}\text { Busca de grupos de pesquisa ativos sobre o tema Gestão Internacional } \\
\text { de Pessoas no diretório da Plataforma Lattes. }\end{array}$ & 7 grupos de pesquisa \\
\hline
\end{tabular}

Fonte: Elaborada pelos autores

\section{RESULTADOS}

A presente seção contempla de forma sintetizada os achados provenientes da análise dos 16 artigos que compuseram a base final da pesquisa por meio de tabelas e gráficos seguindo as categorizações tomadas como referência e revelando a produção científica nacional sobre a Gestão Internacional de Pessoas.

\section{Identificação e demografia}

Concernente à identificação e demografia da produção científica sobre o tema Gestão Internacional de Pessoas, verifica-se, conforme Tabela 1, que a publicação de artigos no período entre janeiro de 2012 e junho de 2017 apresentou um pico no ano de 2016 (37,50\%); a elaboração dos artigos foi realizada majoritariamente com a colaboração de 3 autores (44\%), algumas vezes apontando para uma provável parceria entre orientadores e orientandos de Programas de Pós-Graduação; por fim, destacou-se como maior titulação entre os autores o Doutorado (63\%). 
Tabela 1 - Identificação e Demografia

\begin{tabular}{c|c}
\hline Ano de Publicação & $\%$ \\
\hline 2012 & $18,75 \%$ \\
\hline 2013 & $12,50 \%$ \\
\hline 2014 & $12,50 \%$ \\
\hline 2015 & $18,75 \%$ \\
\hline 2016 & $37,50 \%$ \\
\hline 2017 (até junho) & $0 \%$ \\
\hline Quantidade de autores & $\%$ \\
\hline Dois & $31,00 \%$ \\
\hline Três & $44,00 \%$ \\
\hline Quatro & $19,00 \%$ \\
\hline Cinco & $6,00 \%$ \\
\hline Maior Formação & $\%$ \\
\hline Graduação & $8,00 \%$ \\
\hline Mestrado & $23,00 \%$ \\
\hline Doutorado & $63,00 \%$ \\
\hline Pós-Doutorado & $6,00 \%$ \\
\hline
\end{tabular}

Fonte: Elaborada pelos autores

Por meio da análise das publicações, não foi possível observar a predominância de publicações em uma revista específica (Figura 1), haja vista que se constatou uma pulverização dos 16 artigos em 11 periódicos.

Figura 1 - Distribuição dos artigos por periódico.

Revista Eletrônica de Estratégia \& Negócios (B2)

Revista Eletrônica de Administração - READ (B1)

Revista de Gestão USP - REGE (B1)

Revista de Administração - São Paulo - RAUSP (A2)

Revista de Administração Mackenzie - RAM (B1)

Teoria e Prática em Administração (B2)

Revista Pretexto (B2)

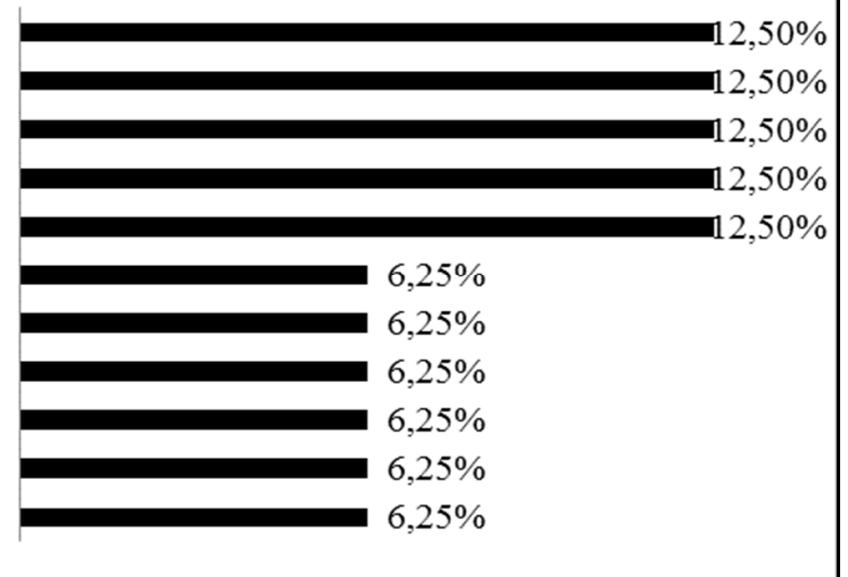

Fonte: Elaborada pelos autores 
Também é possível depreender da Figura 1 que, dos 32 periódicos de Administração mais conceituados segundo o Qualis Capes (Quadriênio 2013-2016), 21 não publicaram um artigo sequer que tratasse de Gestão Internacional de Pessoas, sendo que 6 das 13 revistas B2 foram responsáveis por 43,75\% dos trabalhos, 3 das 10 revistas B1 por 37,50\%, e 2 das 9 revistas A2 por 18,75\%.

Os artigos foram produzidos por 43 diferentes autores, porém apenas 4 deles publicaram mais de um artigo no período analisado (vide Tabela 2), com Shalimar Gallon vinculada à Universidade Federal do Rio Grande do Sul (UFRGS) destacando-se discretamente como a mais produtiva, em nível nacional, nas pesquisas referentes ao tema.

Tabela 2 - Autores que mais publicaram e respectivas instituições de filiação

\begin{tabular}{|c|c|c|}
\hline Autor & Instituição & Quantidade \\
\hline Shalimar Gallon & UFRGS & 3 \\
\hline Betina Magalhães Bitencourt & UFRGS & 2 \\
\hline Bruno Felix von Borell de Araújo & FUCAPE & 2 \\
\hline Elaine Di Diego Antunes & UFRGS & 2 \\
\hline
\end{tabular}

Fonte: Elaborada pelos autores

Os autores são filiados a 24 instituições diferentes e, destas, 8 destacam-se (Figura 2) por terem mais de um autor a elas vinculados: Universidade Federal do Rio Grande do Sul (11), Fundação Instituto Capixaba de Pesquisas em Contabilidade, Economia e Finanças (5), Fundação Getúlio Vargas-RJ (4), Universidade Federal de Uberlândia (4), Escola Superior de Propaganda e Marketing-SP (3), Universidade de São Paulo (3), Universidade Municipal de São Caetano do Sul (3) e Universidade Federal de Santa Catarina (2).

Como consequência de a UFRGS ter a ela vinculados 3 dos 4 autores mais recorrentes no período sobre o tema, ela foi a instituição à qual se relacionou o maior número de artigos, com $11(68,75 \%)$ publicações no total.

Figura 2 - Distribuição de autores por instituição.

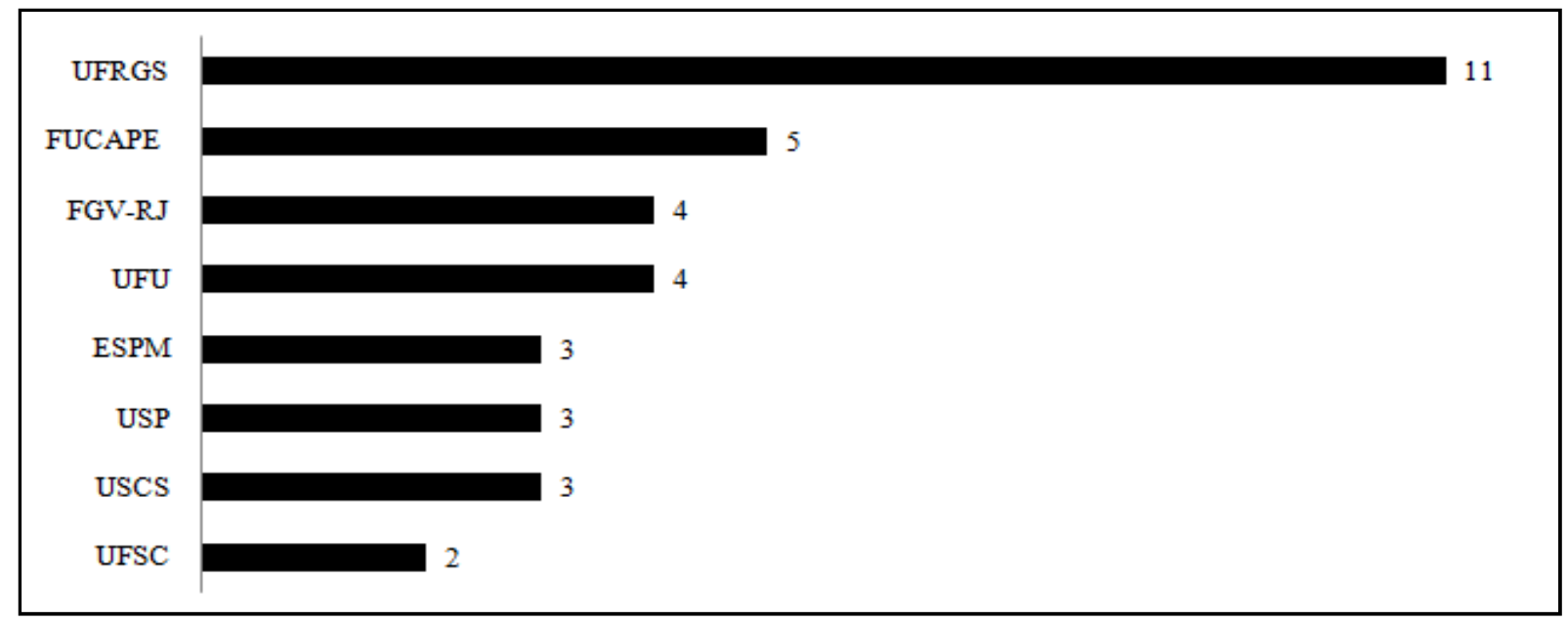

Fonte: Elaborada pelos autores 


\section{Tipificação metodológica}

No tocante à tipificação metodológica e, especificamente, quanto ao enquadramento dos estudos, chamou atenção o fato de que a totalidade dos 16 artigos produzidos quanto à Gestão Internacional de Pessoas no período analisado serem teórico-empíricos, não se identificando nenhum ensaio teórico. A Tabela 3 sumariza as demais dimensões e categorias de análise.

Tabela 3 - Tipificação metodológica

\begin{tabular}{c|c}
\hline Natureza do Estudo & $\%$ \\
\hline Qualitativa & $69,00 \%$ \\
\hline Quantitativa & $25,00 \%$ \\
\hline Multimétodo (Quali-Quanti) & $6,00 \%$ \\
\hline Setor da Economia & $\%$ \\
\hline Privado & $75,00 \%$ \\
\hline Privado e Público & $13,00 \%$ \\
\hline Público & $6,00 \%$ \\
\hline Não informado & $6,00 \%$ \\
\hline
\end{tabular}

Fonte: Elaborada pelos autores

Quanto à natureza, constatou-se a predominância de estudos qualitativos, correspondendo a $69 \%$ do total, seguidos pelas pesquisas quantitativas $(25 \%)$ e multimétodo (6\%). Com relação ao lócus de pesquisa, a maioria dos estudos concentrou-se no setor privado (75\%). No que diz respeito ao ramo de atuação das organizações estudadas, identificou-se uma grande diversificação, dentre eles os ramos metalúrgico, financeiro, agrícola, petroleiro, de energia e de transporte. Exemplo de artigo com a configuração metodológica predominante é aquele desenvolvido por Henriques, Antunes e Macke (2013) com o título "Para além dos aspectos tecnológicos na transferência intercultural de conhecimento: o papel da área de recursos humanos internacional". Nesse artigo, os autores estudaram o caso de uma multinacional americana instalada no Brasil há 33 anos, por meio de entrevistas com gestores de diferentes áreas. Dentre outros pontos, a pesquisa discute o fato de que a área de Recursos Humanos Internacional pode desempenhar um papel importante ao criar condições profícuas para que o conhecimento flua entre as suas subsidiárias. 


\section{Procedimentos e técnicas}

Com respeito aos procedimentos e, especificamente, aos instrumentos de coleta de dados utilizados, destacaram-se a entrevista $(43,75 \%)$ e o questionário (25\%). Nota-se que a entrevista, além de ter sido adotada como única técnica de coleta de dados na maior parcela dos artigos $(43,75 \%)$, também foi utilizada em conjunto com outras técnicas, conforme apresentado na Figura 3.

Figura 3 - Instrumentos de coleta de dados utilizados.

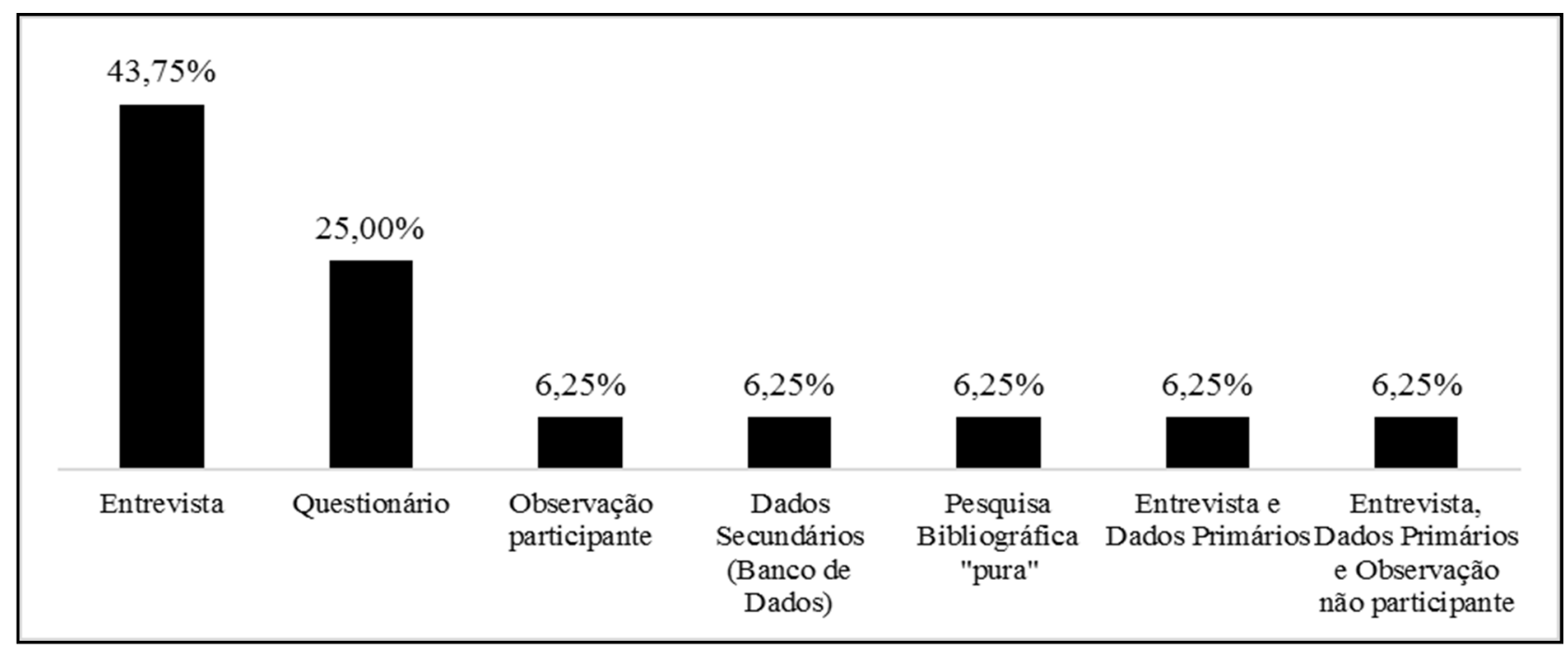

Fonte: Elaborada pelos autores

A técnica de análise de dados mais empregada foi a Análise de Conteúdo (62,50\%). Similarmente, nota-se que a Análise de Conteúdo, além de ter sido adotada como única técnica de análise de dados na maioria dos artigos, também foi utilizada em conjunto com a Análise Multicritério conforme apresentado na Figura 4.

Figura 4 - Técnicas de análise de dados utilizadas.

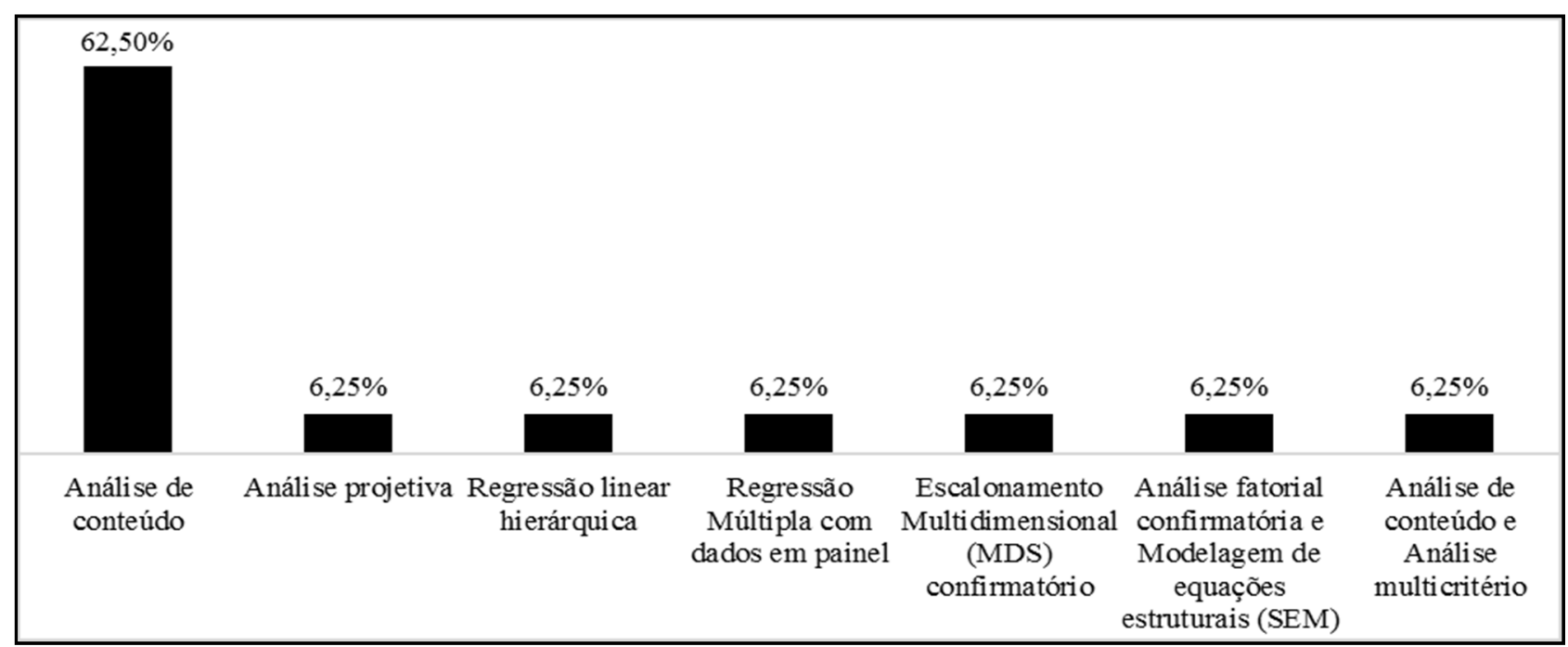

Fonte: Elaborada pelos autores 
Um estudo que representa essa categorização predominante de instrumento de coleta e técnica de análise foi o de Nogueira e Barreto (2013), que pesquisou a mentalidade global e as políticas de recursos humanos internacionais em duas empresas brasileiras. Os resultados do estudo revelaram que, apesar de as empresas analisadas possuírem grande experiência de atuação global, não adotavam políticas de recursos humanos internacionais consistentes que facilitassem o desenvolvimento e a manutenção da mentalidade global de seus gestores.

Quanto aos objetivos dos 16 estudos, predominaram pesquisas cujo intuito principal foi o de aplicação de conceitos e práticas da Gestão Internacional de Pessoas (GIP) nas empresas (56,25\%) acerca de variados subtemas. Concernente à abordagem metodológica da pesquisa, ganhou destaque o Estudo de Caso $(56,25 \%)$ seguido do Survey $(12,50 \%)$. Os demais objetivos e abordagens metodológicas estão detalhados na Tabela 4.

Tabela 4 - Objetivos e abordagens metodológicas do estudo

\begin{tabular}{c|c}
\hline Objetivo & $\%$ \\
\hline Aplicação de conceitos e práticas da GIP nas empresas & $56,25 \%$ \\
\hline Estudo de antecedentes & $12,50 \%$ \\
\hline Estudo de consequentes & $12,50 \%$ \\
\hline Nova proposta teórica & $12,50 \%$ \\
\hline Validação de instrumento & $6,25 \%$ \\
\hline Abordagem metodológica & $\%$ \\
\hline Estudo de caso & $56,25 \%$ \\
\hline Survey & $12,50 \%$ \\
\hline Experimento & $6,25 \%$ \\
\hline Etnografia & $6,25 \%$ \\
\hline Fenomenologia & $6,25 \%$ \\
\hline Survey e Experimento & $6,25 \%$ \\
\hline
\end{tabular}

Fonte: Elaborada pelos autores

Nota-se que o Estudo de Caso, Survey, Experimento e Pesquisa Documental foram abordagens utilizadas de forma conjunta em alguns artigos.

\section{Enfoque temático}

Dentre os enfoques temáticos, destacou-se o da Expatriação $(56,25 \%)$ seguido do Desenvolvimento de competências de gestão de recursos humanos em contexto internacional (18,75\%). Um dos artigos analisados que retratam o enfoque da Expatriação é o de Araújo et al. (2012). Em seu estudo, os autores buscaram diferenciar particularidades da adaptação de dois tipos de expatriados: voluntários e organizacionais, sendo os primeiros aqueles que não são designados pela empresa para trabalhar no exterior e os últimos aqueles que o são. Já o enfoque temático de desenvolvimento de competências internacionais pode ser exemplificado pelo estudo de Reis, Borini e Floriani (2012), o qual concluiu que determinados fatores 
culturais podem inibir tal desenvolvimento nas subsidiárias estrangeiras. Os demais enfoques temáticos são descritos na Tabela 5.

Tabela 5 - Enfoque temático

\begin{tabular}{c|c}
\hline Enfoque temático & $\%$ \\
\hline Expatriação & $56,25 \%$ \\
\hline Desenvolvimento de Competências Internacinonais & $18,75 \%$ \\
\hline Repatriação & $12,50 \%$ \\
\hline O papel da área de RH Internacional & $12,50 \%$ \\
\hline
\end{tabular}

Fonte: Elaborada pelos autores

A carência de estudos cujo foco temático fuja de aspectos burocráticos de expatriação e repatriação, identificada nos resultados deste estudo, potencialmente prejudica o aspecto estratégico daquelas empresas que buscam expandir seus negócios além das fronteiras geográficas e culturais. $\mathrm{O}$ aprofundamento científico sobre o tema pode subsidiar a prática de gestão internacional de pessoas.

Como apontam Bohlander, Snell e Sherman (2003), as organizações precisam buscar selecionar colaboradores cada vez mais capazes de lidar com a diversidade cultural e com uma grande capacidade de adaptação. Embora as empresas globais tendam a utilizar as fontes convencionais de recrutamento, seu processo de seleção se torna mais criterioso por exigir, além da qualificação necessária, a identificação com a cultura e idioma do país anfitrião (SNELL e BOHLANDER, 2011).

\section{Institucionalização da pesquisa no Brasil}

O retrato contemporâneo da institucionalização da pesquisa no Brasil sobre a Gestão Internacional de Pessoas foi obtido a partir da identificação dos grupos de pesquisa no respectivo diretório da Plataforma Lattes em julho de 2017, tendo a pesquisa retornado para os descritores "Gestão Internacional", "Internacionalização", "Expatriação", "Expatriado" e "Repatriação". Os nomes, linhas de pesquisa e repercussões dos trabalhos dos grupos resultantes da busca foram lidos a fim de se identificarem aqueles relacionados ao tema foco desta pesquisa. Chegou-se ao número final de 7 grupos que tivessem ao menos uma linha de pesquisa relacionada ao tema.

É importante destacar que nenhum dos grupos identificados apresentou a Gestão Internacional de Pessoas como principal norteador, sendo esse tema apenas uma das linhas de pesquisa dos grupos, o que aponta para uma relação apenas indireta. Os resultados da busca para os descritores supracitados e que foram descartados não tinham relação direta com a Gestão Internacional de Recursos Humanos, abordando temas como Comunicação mercadológica, Marketing, Inovação, Comércio Exterior, Direito Internacional, Política Internacional, Finanças internacionais, dentre outros. Os dados resumidos concernentes ao ano de criação, nome, instituição de filiação e área dos grupos selecionados estão resumidos no Quadro 3. 
Quadro 3 - Grupos de pesquisa

\begin{tabular}{|c|c|c|c|}
\hline Ano de Criação & Nome & Instituição & Área \\
\hline 2002 & $\begin{array}{c}\text { Gestão de Pessoas e Gestão do Conhecimento nas } \\
\text { Organizações }\end{array}$ & USP & Administração \\
\hline 2002 & $\begin{array}{c}\text { Grupo de Estudos em Gestão Social, Mudanças, } \\
\text { Aprendizagem e Competências Organizacionais } \\
\text { (GESMAC) }\end{array}$ & UNISINOS & Administração \\
\hline 2002 & $\begin{array}{c}\text { Grupo de Pesquisa Internacionalização e } \\
\text { Desenvolvimento }\end{array}$ & UFS & Economia \\
\hline 2007 & Estratégia e Competitividade & UNINOVE & Administração \\
\hline 2011 & GAIA & PUC-MG & Administração \\
\hline 2013 & Dinâmica Evolutiva das Organizações Humanas & UFMS & Administração \\
\hline 2015 & $\begin{array}{l}\text { Núcleo de Estudos em Gestão Organizacional e } \\
\text { Tecnologias Gerenciais (NEG) }\end{array}$ & UFMG & Administração \\
\hline
\end{tabular}

Fonte: Elaborada pelos autores

Dentre os 7 grupos selecionados, 2 se destacaram por apresentar maior relação com o tema foco deste estudo. O Grupo de Estudos em Gestão Social, Mudanças, Aprendizagem e Competências Organizacionais (GESMAC), vinculado à Universidade do Vale do Rio dos Sinos (UNISINOS), foi aquele com maior ligação com o tema Gestão Internacional de Pessoas. Já o Grupo GAIA, da Pontifícia Universidade Católica de Minas Gerais (PUC-MG), foi aquele com maior ligação com o tema Expatriação. É importante ressaltar que, entre os líderes dos 7 grupos de pesquisa supracitados, nenhum foi encontrado como autor dos artigos selecionados neste estudo bibliométrico acerca do tema Gestão Internacional de Pessoas. A partir do Quadro 3 , também é possível perceber que não há uma instituição de destaque com grupos de pesquisa vinculados a ela sobre o tema. A Universidade Federal do Rio Grande do Sul (UFRGS), que se destacou como instituição de vínculo de 11 autores dos artigos selecionados na presente bibliometria, não apresentou na busca grupo de pesquisa relacionado à Gestão Internacional de Pessoas.

\section{Agenda de pesquisa}

Os resultados desta pesquisa demonstraram que o campo de pesquisa relativo à Gestão Internacional de Pessoas ainda pode ser considerado em desenvolvimento no Brasil, respaldando a afirmação de Silva, Orsi e Nakata (2013), que consideraram esse tema recente tanto no contexto internacional quanto no nacional. A bibliometria realizada para o período de janeiro de 2012 a junho de 2017 evidenciou uma deficiência da produção científica nacional, com apenas 16 artigos sobre o tema, o que se traduz em importante lacuna na literatura, haja vista a importância estratégica do tema para as instituições. Ademais, é interessante notar que, dentre os artigos selecionados, a maioria $(56,25 \%)$ tratou do assunto "Expatriação", comprovando as afirmações de Schuler e Tarique (2007). Esses autores dizem que estudos concernentes à Gestão Internacional de Recursos Humanos são escassos, sendo que a maioria das pesquisas existentes 
foca em questões operacionais de expatriados, detalhando o processo de expatriação e suas respectivas políticas e práticas.

A deficiência da produção científica nacional acerca do tema também foi salientada pela ausência de grupo de pesquisa no Brasil cujo principal norteador seja o estudo da Gestão Internacional de Recursos Humanos. Essa temática foi identificada somente em 7 grupos de pesquisa e apenas como uma das várias linhas de pesquisa adotadas, demonstrando uma relação apenas indireta. Não se pode deixar de mencionar também que a baixa concentração da condução dos estudos, demonstrada pela pulverização das instituições de vínculo dos poucos grupos de pesquisa, aponta para a falta de consolidação das investigações relativas ao tema.

Quanto ao ponto de vista metodológico, este estudo bibliométrico demonstrou que os pesquisadores brasileiros optaram em sua maioria por estudos qualitativos no setor privado respaldados em entrevistas como instrumento de coleta de dados e em análise de conteúdo como técnica de análise, o que pode contribuir para dificuldades de generalização dos resultados. Houve também significativa predominância de estudos cujo objetivo principal foi o de aprofundamento acerca do tema com abordagem metodológica de estudo de caso.

Dessa maneira, sugere-se a seguinte agenda de pesquisa sobre Gestão Internacional de Pessoas: realização de estudos no primeiro e terceiro setores; promoção de pesquisas quantitativas ou multimétodo; e investigações relativas a temas pouco explorados entre 2012 e 2017 como, por exemplo, o papel e importância do RH internacional, fugindo de um enfoque puramente operacional sobre os processos de expatriação. O desenvolvimento de estudos multimétodo, os quais mesclam abordagens qualitativa e quantitativa, possibilitam a propalada triangulação metodológica, permitindo uma melhor compreensão do fenômeno ao mesmo tempo em que esforços para compreendê-lo ou mensurá-lo são engendrados. Tais estudos permitirão um entendimento mais amplo sobre os fenômenos da Gestão Internacional de Pessoas, respaldando metodologicamente as maneiras pelas quais a gestão de pessoas deve ser trabalhada em um cenário multicultural. Por fim, sugere-se a elaboração de ensaios teóricos visando à maior divulgação e compreensão do tema específico, já que a revisão de literatura não foi o objetivo principal de nenhum dos 16 artigos selecionados no estudo.

\section{CONSIDERAÇÕES FINAIS}

O presente estudo realizou uma análise bibliométrica acerca da produção científica no Brasil sobre a Gestão Internacional de Pessoas no período compreendido entre janeiro de 2012 e junho de 2017, dando sequência à bibliometria de Silva, Orsi e Nakata (2013), haja vista que o referido estudo teve como marco final a produção nacional e internacional sobre o tema até 2011. Tal qual desvelou a bibliometria de Silva, Orsi e Nakata (2013), os resultados da presente bibliometria apontaram a escassez e subsequente necessidade de estudos sobre modelos de gestão internacional de recursos humanos, visto que o cenário nacional também tem priorizado as questões relativas à expatriação.

Este trabalho contribui para a área de Gestão de Recursos Humanos, uma vez que aponta, por meio do mapeamento realizado, caminhos para o desenvolvimento mais profundo da Gestão Internacional de Pessoas por meio de pesquisas futuras. Outra contribuição do trabalho diz respeito à identificação da institucionalização da pesquisa brasileira sobre o tema. 
Alguns autores, a exemplo de Silva, Orsi e Nakata (2013), justificam a baixa produção acadêmica brasileira sobre o tema pelo fato de o mesmo ter se tornado relevante somente a partir da primeira década do século XXI, com o movimento das empresas nacionais para o exterior. Todavia esse movimento recente não pode ser considerado uma justificativa satisfatória, em virtude de a presença de multinacionais estrangeiras no Brasil ser antiga, datada de meados do século XX, já ponderado pelos referidos autores. Nessa ótica, apresentamos como sugestão de pesquisas futuras um maior aprofundamento da gestão internacional de pessoas no Brasil, no propósito de verificar especificamente se temos em nosso país realidades diferenciadas que o posicionem como foco de atenção se comparado ao quadro internacional. Adicionalmente, sugere-se a realização de estudos que detalhem quais temáticas exploradas internacionalmente já estão consolidadas no Brasil.

O presente estudo, ao alargar o escopo temporal bibliométrico sobre a gestão internacional de pessoas no contexto brasileiro, acentuou os achados da pesquisa tomada como seu ponto de partida, no sentido de ter confirmado a permanente incipiência do tema em nosso país, bem como ter demonstrado a desconexão dos autores brasileiros mais recorrentes e os líderes de grupos de pesquisa sobre o tema, o que aponta para a fragilidade da institucionalização da área.

Algumas limitações do estudo podem ser identificadas, dentre as quais o não esgotamento da literatura nacional concernente ao assunto, uma vez que foram selecionados periódicos com estrato Qualis igual ou superior a B2, objetivando retratar a produção nacional de primeira linha. Sendo assim, alguns periódicos mais fortemente ligados ao tema principal não foram considerados por terem classificação inferior a B2 no Qualis. Ademais, outra limitação refere-se à não inclusão de artigos apresentados em eventos importantes de Administração como, por exemplo, o ENANPAD, por serem considerados trabalhos em construção.

Encerra-se o artigo esperando ter contribuído para que outras discussões e pesquisas possam ser derivadas dessa exposição. Afinal, o fato de a temática ser pouco estudada no país, traz, por si, grandes oportunidades de pesquisa que possam dar base científica à gestão organizacional, tornando-a mais efetiva. 


\section{REFERÊNCIAS}

ARMSTRONG, M. Armstrong's Handbook of Strategic Human Resource Management. London: Kogan Page, 2011.

ARAÚJO, R. F.; ALVARENGA, L. A bibliometria na pesquisa científica da pós-graduação brasileira de 1987 a 2007. Revista Eletrônica de Biblioteconomia, v. 16, n.31, p. $\quad$ 51-70, $2011 . \quad$ URL: https://periodicos.ufsc.br/index.php/eb/article/view/1518-2924.2011v16n31p51

ARAÚJO, B. F. von B. de; TEIXEIRA, M. L. M.; CRUZ, P. B. da; MALINI, E. Adaptação de expatriados organizacionais e voluntários: similaridades e diferenças no contexto brasileiro. Revista de Administração - RAUSP, v. 47, n. 4, p. 555-570, 2012. URL: http://www.scielo.br/pdf/rausp/v47n4/a04v47n4.pdf

BOHLANDER, G.; SNELL, S.; SHERMAN, A. Administração de recursos humanos. 1 ed. São Paulo: Cengage Learning, 2003. $547 p$

BOLINO, M. C.; FELDMAN, D. C. Increasing the skill utilization of expatriates. Human Resource Management, v. 39, n. 4, p. 369-380, 2000. URL: http://onlinelibrary.wiley.com/doi/10.1002/1099-050X(200024)39:4\%3C367::AIDHRM7\%3E3.0.CO;2-7/full.

BUENO, J. M.; FREITAS, M. E. de. Representações Sociais e Gestão Intercultural nas Organizações. XXXV Encontro da ANPAD, Rio de Janeiro, set. 2011. Disponível em: <http://www.anpad.org.br/admin/pdf/GPR566.pdf>. Acesso em: 03. mai. 2018

CALDERÓN, P. A. L.; GUEDES, A. L. M.; CARVALHO, R. W. Gestão internacional de recursos humanos: Adaptabilidade intercultural na expatriação de brasileiros. InternexT - Revista Eletrônica de Negócios Internacionais da ESPM, v. 11, n. 2, p. 6-20, 2016. URL: http://internext.espm.br/index.php/internext/article/view/344.

FLEURY, A.; FLEURY, M. T. L. Internacionalização das empresas brasileiras: em busca de uma abordagem teórica para os late movers. In: A. Fleury, M. T. L. Fleury (Org.) Internacionalização e os Países Emergentes. São Paulo: Atlas, 2007.

GALLON, S.; GARAY, A. B. S.; BITENCOURT, B. M. Expatriação como processo estratégico nas empresas internacionalizadas. XXXVI Encontro da ANPAD, Rio de Janeiro, Brasil, 36, $2012 . \quad$ URL: http://www.anpad.org.br/admin/pdf/2012_GPR880.pdf.

GALLON, S.; SCHEFFER, A. B. B.; BITENCOURT, B. M. A expatriação e o seu papel estratégico nas empresas internacionalizadas. Revista Eletrônica de Negócios Internacionais, v. 9, n. 3, p. 38-56, 2014. URL: https://www.lume.ufrgs.br/bitstream/handle/10183/126288/000972401.pdf?sequence=1

GUO, C.; AL ARISS, A. Human resource management of international migrants: current theories and future research. The International Journal of Human Resource Management, v. 26, n. 10, p. 1287-1297, 2015. DOI: 10.1080/09585192.2015.1011844

HENRIQUES, A. C. V.; ANTUNES, E. D. D.; MACKE, J. Para além dos aspectos tecnológicos na transferência intercultural de conhecimento: o papel da área de recursos humanos internacional. Revista Eletrônica de Administração, v. 74, n. 1, p. 247-273., 2013. URL: http://www.scielo.br/scielo.php?pid=S1413-23112013000100010\&script=sci_abstract\&tlng=pt

HILL, C. W. L. International Business: Competing in the Global Marketplace. New York, NY: McGraw-Hill, 2005.

HOFSTEDE, G. Culture's consequences: Comparing values, behaviors, institutions and organizations across nations. Thousand Oaks: Sage, 2001.

KOSTOVA, T.; ROTH, K.; DACIN, M. T. Institutional theory in the study of multinational corporations: A critique and new directions. Academy of management review, v. 33, n. 4, p. 994-1006, $2008 . \quad$ URL: http://amr.aom.org/content/33/4/994.abstract

LAURENT, A. The cross-cultural puzzle of international human resource management. Human Resource Management, $v$. 25, p. 91-102, 1986. DOI: 10.1002/hrm.3930250107

LIMA, L. C. Gestão internacional de recursos humanos e desafios a serem superados. Revista Eletrônica de Negócios Internacionais, v. 11, n. 2, p. 1-5, 2016. URL: http://internext.espm.br/index.php/internext/article/view/376

MILLER, E. L. The international selection decision: A study of some dimensions of managerial behavior in the selection Decision Process. Academy of Management Journal, v. 16, n. 2, p. 239-252, $1973 . \quad$ URL: https://www.jstor.org/stable/255325?seq=1\#page_scan_tab_contents

MOBILITY BRASIL. Global Line em parceria com a FIA, ABRH-RJ e ABRH-SP, $2016 . \quad$ URL: http://www.gline.com.br/mobility_brasil_2016.pdf

NOGUEIRA, A. M.; BARRETO, M. S. P.; DELGADO, M. P. Gestão de recursos humanos no processo de internacionalização. Revista Eletrônica de Negócios Internacionais, v. 8, n. 1, p. 48-67, 2013. URL: http://internext.espm.br/index.php/internext/article/view/150 
PUCIK, V. Human resources in the future: an obstacle or a champion of globalization. Human Resource Management, v. 36, $\quad$ p. $166-167, \quad 1997 . \quad$ URL: https://digitalcommons.ilr.cornell.edu/cgi/viewcontent.cgi?referer=https://www.google.com.br/\&httpsredir=1\&article=1180 \&context=cahrswp

REIS, G. G.; BORINI, F. M.; FLORIANI, D. E. A relação entre Global Mindset e capacidades adaptativas em empresas internacionalizadas. Revista Alcance, v. 19, n. 4, p. $\quad$ 556-573, $2012 . \quad$ URL: https://siaiap32.univali.br/seer/index.php/ra/article/download/3203/2450.

REMONDES, J.; VINHAS, J. A problemática da expatriação na gestão internacional de recursos humanos: estudos aplicados em PME do centro e norte de Portugal. Revista Eletrônica de Negócios Internacionais, v. 9, n. 3, p. 16-37, 2014. URL: http://www.spell.org.br/documentos/ver/33703/a-problematica-da-expatriacao-na-gestao-internacional-de-recursoshumanos--estudos-aplicados-em-pme-do-centro-e-norte-de-portugal

REYNOLDS, C. Global Compensation and benefits in transition. Compensations and Benefits Review, v. 32, n. 1, p. 2838, 2000. URL: http://journals.sagepub.com/doi/abs/10.1177/088636870003200105?journalCode=cbrb

SCHULER, R.; TARIQUE, I. International human resource management: a North American perspective, a thematic update and suggestions for future research. The International Journal of Human Resource Management, v. 18, n. 5, p. 717-744, 2007. DOI: $10.1080 / 09585190701246590$

SILVA, N. B.; ORSI, A.; NAKATA, L. E. Análise da Produção Acadêmica sobre Gestão Internacional de Recursos Humanos entre 2001 e 2011. Revista de Carreiras \& Pessoas, v. 3, n. 3, p. 50-60, 2013. URL: https://revistas.pucsp.br/index.php/ReCaPe/article/view/17703

SIMONELLI, B. T.; ARAÚJO, B. F. von B. de. Adaptação de cônjuges e de expatriados e sua relação com o desempenho em designações internacionais. Revista Eletrônica de Negócios Internacionais, v. 11, n. 2, p. 21-34, 2016. URL: http://internext.espm.br/index.php/internext/article/view/323.

SNELL, S.; BOHLANDER, G. Administração de recursos humanos. São Paulo: Cengage Learning, 2011. 570 p.

TANURE, B.; DUARTE, R. G. O impacto da Diversidade Cultural na gestão Internacional. In: Tanure, B.; Duarte, R. G. (Org.). Gestão Internacional. São Paulo: Saraiva, 2006.

TAGUE-SUTCLIFFE, J. An introduction to informetrics. Information processing \& management, Oxford, v. 28, n. 1, p. 1-3, 1992. URL: https://www.sciencedirect.com/science/article/abs/pii/030645739290087G

TAYLOR, S.; BECHLER, S.; NAPIER, N. Toward an integrative model of strategic international human resource management. Academy of Management Review, v. 21, n. 4, p. 959-985, 1996. URL: https://www.jstor.org/stable/259160

VANCE, C. M.; PAIK, Y. Managing a Global Workforce-Challenges and Opportunities. London: M. E. Sharpe, 2006. 